\title{
Enhancing the efficiency of electrochemical desalination of stones: a proton pump approach
}

Feijoo, Jorge; Nóvoa, X. R.; Rivas, Teresa; Ottosen, L. M.

Published in:

Materials and Structures

Link to article, DOI:

$10.1617 / \mathrm{s} 11527-018-1224-x$

Publication date:

2018

Document Version

Peer reviewed version

Link back to DTU Orbit

Citation (APA):

Feijoo, J., Nóvoa, X. R., Rivas, T., \& Ottosen, L. M. (2018). Enhancing the efficiency of electrochemical desalination of stones: a proton pump approach. Materials and Structures, 51(4), [100].

https://doi.org/10.1617/s11527-018-1224-x

\section{General rights}

Copyright and moral rights for the publications made accessible in the public portal are retained by the authors and/or other copyright owners and it is a condition of accessing publications that users recognise and abide by the legal requirements associated with these rights.

- Users may download and print one copy of any publication from the public portal for the purpose of private study or research.

- You may not further distribute the material or use it for any profit-making activity or commercial gain

- You may freely distribute the URL identifying the publication in the public portal

If you believe that this document breaches copyright please contact us providing details, and we will remove access to the work immediately and investigate your claim. 


\section{Materials and Structures \\ Enhancing the efficiency of electrochemical desalination of stones: A proton pump approach \\ --Manuscript Draft--}

\begin{tabular}{|c|c|}
\hline Manuscript Number: & MAAS-D-17-01317R2 \\
\hline Full Title: & $\begin{array}{l}\text { Enhancing the efficiency of electrochemical desalination of stones: A proton pump } \\
\text { approach }\end{array}$ \\
\hline Article Type: & Original Research \\
\hline Keywords: & Electro-migration; electro-osmosis; desalination; sandstone; soluble salts \\
\hline Corresponding Author: & $\begin{array}{l}\text { Jorge Feijoo, PhD } \\
\text { Universidade de Vigo } \\
\text { Vigo, Pontevedra SPAIN }\end{array}$ \\
\hline \multicolumn{2}{|l|}{$\begin{array}{l}\text { Corresponding Author Secondary } \\
\text { Information: }\end{array}$} \\
\hline Corresponding Author's Institution: & Universidade de Vigo \\
\hline \multicolumn{2}{|l|}{$\begin{array}{l}\text { Corresponding Author's Secondary } \\
\text { Institution: }\end{array}$} \\
\hline First Author: & Jorge Feijoo, PhD \\
\hline \multicolumn{2}{|l|}{ First Author Secondary Information: } \\
\hline \multirow[t]{4}{*}{ Order of Authors: } & Jorge Feijoo, PhD \\
\hline & X.R. Nóvoa, PhD \\
\hline & Teresa Rivas, PhD \\
\hline & L.M. Ottosen, PhD \\
\hline \multicolumn{2}{|l|}{ Order of Authors Secondary Information: } \\
\hline \multicolumn{2}{|l|}{ Funding Information: } \\
\hline Abstract: & $\begin{array}{l}\text { Soluble salts are among the most harmful alteration agents affecting the building } \\
\text { materials. In recent years, several researches have been devoted to counteract } \\
\text { alterations induced by soluble salts using electrokinetic techniques. However, the } \\
\text { applicability of these techniques for conservation purposes remains limited due to } \\
\text { adverse side effects, such as the extreme pH values occurring near the electrodes, } \\
\text { which can affect the stone to be treated. The decrease in efficiency of the treatment } \\
\text { caused by the dominant transport of } \mathrm{H}+\text { and } \mathrm{OH} \text { - groups is also an undesired effect. } \\
\text { The reduced duration of these treatments due to the drying of the material in contact } \\
\text { with the anode also limits their practical use. To overcome these problems, a new } \\
\text { electrokinetic design that includes a so called proton pump is presented in this report. } \\
\text { This design is based on placing two electrodes in the anodic compartment in order to } \\
\text { modulate the net amount of } \mathrm{H}+\text { produced. The design was applied to desalinate } \\
\text { sandstone samples contaminated with several soluble salts. The application of this } \\
\text { new approach allowed us to establish an additional electroosmotic process at the } \\
\text { anode, which was able to increase the duration of the treatment. Moreover, the new } \\
\text { setup provided improved pH buffer ability due to the generation of OH- in the anodic } \\
\text { compartment, which increased the effectiveness of the treatment by hindering the } \\
\text { entrance of } \mathrm{H}+\text { in the porous structure. }\end{array}$ \\
\hline Response to Reviewers: & $\begin{array}{l}\text { Following the advice of the editor, the paper was reviewed by a native speaker of } \\
\text { English, which has made several changes, including the title. }\end{array}$ \\
\hline \multicolumn{2}{|l|}{ Additional Information: } \\
\hline Question & Response \\
\hline $\begin{array}{l}\text { Provide the total number of words in the } \\
\text { manuscript (excluding figure caption and }\end{array}$ & 7915 \\
\hline
\end{tabular}


table caption)?

Provide total number of FIGURES? 12

Provide total number of TABLES?

3 
Enhancing the efficiency of electrochemical desalination of stones: A proton pump approach

Jorge Feijoo*

Ph.D. Dep. Ingeniería de los Recursos Naturales y Medio Ambiente, Universidad de Vigo, Lagoas-Marcosende s/n, 36310 Vigo, Spain.jfeijoo@uvigo.es

X.R. Nóvoa

Ph.D. Dep. Chem. Eng., ENCOMAT group, EEI. University of Vigo. 36310 Vigo-Spain, Lagoas-Marcosende s/n, 36310 Vigo, Spain.rnovoa@uvigo.es

Teresa Rivas

Ph.D. Dep. Ingeniería de los Recursos Naturales y Medio Ambiente, Universidad de Vigo, Lagoas-Marcosende s/n, 36310 Vigo,Spain.trivas@uvigo.es

L.M. Ottosen

Department of Civil Engineering Building 117, Technical University of Denmark, 2800 Kgs. Lyngby, Denmark. lo@byg.dtu.dk

* Corresponding author 


\begin{abstract}
:
Soluble salts are among the most harmful alteration agents affecting the building materials. In recent years, several researches have been devoted to counteract alterations induced by soluble salts using electrokinetic techniques. However, the applicability of these techniques for conservation purposes remains limited due to adverse side effects, such as the extreme $\mathrm{pH}$ values occurring near the electrodes, which can affect the stone to be treated. The decrease in efficiency of the treatment caused by the dominant transport of $\mathrm{H}^{+}$and $\mathrm{OH}^{-}$groups is also an undesired effect. The reduced duration of these treatments due to the drying of the material in contact with the anode also limits their practical use. To overcome these problems, a new electrokinetic design that includes a so called proton pump is presented in this report. This design is based on placing two electrodes in the anodic compartment in order to modulate the net amount of $\mathrm{H}^{+}$produced. The design was applied to desalinate sandstone samples contaminated with several soluble salts. The application of this new approach allowed us to establish an additional electroosmotic process at the anode, which was able to increase the duration of the treatment. Moreover, the new setup provided improved $\mathrm{pH}$ buffer ability due to the generation of $\mathrm{OH}^{-}$in the anodic compartment, which increased the effectiveness of the treatment by hindering the entrance of $\mathrm{H}^{+}$in the porous structure.
\end{abstract}

Keywords: Electro-migration, electro-osmosis, desalination, sandstone, soluble salts 


\section{Introduction}

The damage caused by the action of the soluble salts puts at risk the perdurability of the buildings that are affected, mainly those that are part of the cultural heritage. To solve this problem, various techniques have been developed to remove or reduce -as far as possible- the soluble salts present inside of the porous materials used in their construction. Among these techniques, the electrokinetic method stands out for the high efficiency in the extraction of soluble salts, both in the laboratory [1-8] and in situ [9-12]. Using this methodology, salt reduction percentages close to $100 \%$ can be reached, even at a considerable depth into the material, as demonstrated in [5], where 6-cm thick granite samples were completely desalinated. However, the electrokinetic treatments have several disadvantages, which must be overcome for their application, including:

- Extreme changes in $\mathrm{pH}$ around the electrodes, due to water hydrolysis. These extreme $\mathrm{pH}$ values can lead to chemical alteration of the materials [1, 5-8, 13-15].

- Colour changes in the treated material due to oxidation, hydrolysis, and solubilisation of some minerals, mainly those containing iron $[13,16]$.

- Generation of microfractures due to the stresses caused by the electric field across the pores of the materials [17], especially those materials containing piezoelectric minerals [18-20], such as quartz.

The main solutions so far suggested to mitigate these adverse effects consist of the use of a buffer electrolyte and in the interposition of a poultice between the electrodes and the material to be treated. The poultice contains calcium carbonate in the anode, as stated in some studies [5$7,10,15]$, and kaolin in the cathode [5-7].

In the traditional electrokinetic methods, there is also an important factor that affects efficiency, defined as the percentage of ion content after passing a certain charge. During this process, the generation of a high quantity of $\mathrm{OH}^{-}$and $\mathrm{H}^{+}$decreases the efficiency because these ions have a mobility higher than that of the ions to be removed. This makes $\mathrm{OH}^{-}$and $\mathrm{H}^{+}$the 
main responsible for the transport of the electrical current. Consequently, the mobilization of the ions of interest decreases and their transport number decreases, thereby decreasing the removal efficiency of the method [11, 15, 21-24].

The solution proposed to this problem lies in retaining -as far as possible- the $\mathrm{OH}^{-}$and $\mathrm{H}^{+}$ions within the poultices that are in contact with the electrodes $[5-7,10,15]$, thus avoiding their entrance in the material. Such a solution increases the transport number of the ions to be removed.

Moreover, in this kind of treatment, it is important to maintain a high humidity level both in the poultices and in the porous structure to be treated, to allow a homogeneous distribution of the electrical current. During the treatment, and following several types of researches [16, 25-27], an electroosmotic process takes place due to the higher intrinsic solvation of cations in the majority of porous materials, which tend to accumulate water in the cathode side. However, at the anode the opposite phenomenon occurs, which causes drying of the material located at this electrode.

The subsequent drying of the material at the anode becomes a limiting factor regarding the time of application of the technique, because the drying worsens the contact between the electrode and the material located at the anode and hinders the current flow $[1,10-11,16]$. No technical solution to solve this problem has been developed. Only two solutions seem feasible: frequent replacement of the material in contact with the anode, or periodical wetting of this material by addition of fresh electrolyte.

This work focuses on the evaluation of a new electrokinetic configuration based on the use of two electrodes in the anodic compartment between which different potentials are applied. Using such an electrokinetic configuration, an increase of the duration of treatment is expected. This is due to the establishment of an electroosmotic process in the anode that compensates the loss of water. Moreover, the $\mathrm{pH}$ buffering capacity of the system will be increased, which will increase the effectiveness of the ion removal. 


\section{Materials and Methods}

\subsection{Porous material used}

An ashlar of yellow sandstone extracted from the Kronborg castle located at the Oresund's Strait entrance (Denmark) was employed for this study. Ten stone cubes $\left(5 \times 5 \times 5 \mathrm{~cm}^{3}\right)$ and 12 stone prisms $\left(6 \times 6 \times 3 \mathrm{~cm}^{3}\right)$ were obtained from this ashlar.

Using the cubic-shaped samples, accessible porosity to water, water absorption coefficient, capillary porosity, and capillarity coefficient were calculated following the various European standards [28-29], and procedures established in different researches [30]. Mercury accessible porosity was determined using a Micromeritics Autopore IV9500 porosimeter that works with two pressure ranges, $0.20 \mathrm{Mpa}-225 \mathrm{MPa}$ (high pressure) and $14 \mathrm{kPa}-0.20 \mathrm{MPa}$ (low pressure). The pore network charge (zeta potential) was determined using a Zetasizer Nano Z, from Malvern Instruments.

The prismatic shaped samples were used for the evaluation of the desalination treatment. The prisms were contaminated with a saline solution composed of $9.9 \% \mathrm{NaNO}_{3}, 6.6$ $\% \mathrm{NaCl}$, and $0.66 \% \mathrm{CaSO}_{4}$ in weight. The contamination cycles consisted of 3 days of capillary absorption followed by a drying process of 2 days at room temperature. Before starting the next contamination cycle, the prisms were turned over to put the opposite face in contact with the solution, trying to achieve a distribution of salts as homogeneous as possible. Five contamination cycles were conducted.

At the end of the contamination cycles, three prisms were used to calculate the initial ion content (the reference value). For this, the prisms were segmented into four pieces (previously labelled on all the sandstone prisms) by hammer and chisel, weighed, and crushed using a pulverizer ring mill. The powder obtained from each piece was homogenized. Three powder samples $(10 \mathrm{~g}$ each $)$ were taken from each piece. The powder samples were maintained under stirring in $25 \mathrm{~mL}$ of ultrapure water for $24 \mathrm{~h}$, and filtered through $0.45-\mu \mathrm{m}$ nitrocellulose filters. The anion content $\left(\mathrm{Cl}^{-}, \mathrm{SO}_{4}{ }^{2-}\right.$, and $\left.\mathrm{NO}_{3}{ }^{-}\right)$and the cation content $\left(\mathrm{Ca}^{2+}\right.$ and $\left.\mathrm{Na}^{+}\right)$were 
obtained from the extracts using high resolution chromatography (Dionex ICS-100) and inductively coupled plasma optical emission spectrometry (Varian 720-ES inductively coupled plasma optical emission spectrometry), respectively. Also, conductivity (EC-Metro BASIC 30), using the normalized equation of Unhruh [31] and $\mathrm{pH}(\mathrm{pH}-$-meter BASIC 20) were measured in each extraction.

The remaining nine stone prisms were used to perform each of the programmed desalination tests (three stone samples per test).

\subsection{Description of the Electrochemical Setups.}

Two different assemblies were prepared for this study. One of these, the 'Traditional Setup', has been widely used in several types of research $[2,11]$, which here we refer to as T-S. This assembly consists of two cells: one is the anodic compartment (called in this study as medium 2, Figure 1), which hosts electrode 2, and the other is the cathodic compartment, which hosts electrode 3. The second assembly corresponds to the 'Double Anode Setup' which here we refer to as DA-S; this assembly has one more cell in the anodic compartment (medium 1, Figure 1), to host another electrode (electrode 1). The electric field established between electrode 1 and electrode 2 works as a proton pump, i.e., a system that allows for modulating of the net amount of $\mathrm{H}^{+}$produced at the anode (medium 2 in Figure $1 \mathrm{~b}$ ) by pumping unwanted protons from medium 2 to medium 1.

\section{INSERT FIGURE 1}

In the T-S setup, one power supply was used (Power supply 2, Figure 2). In the DA-S setup, two power supplies connected in series (Figure 2) were necessary to regulate the current flowing through each cell.

In the two setups (T-S and DA-S), a constant voltage of 8V was established between electrode 2 and electrode 3 using the Power Supply 2 (Figure 2). In the DA-S setup, electrode 1 
was polarized using the Power Supply 1 (Figure 2). With this setup, two different assays were performed, applying two different potentials between the electrodes located in the anodic compartment (electrodes 1 and 2): DA-S2 with $\Delta \mathrm{V}_{1-2}=2 \mathrm{~V}$ and DA-S3 with $\Delta \mathrm{V}_{1-2}=4 \mathrm{~V}$. These different potentials were applied in order to evaluate the magnitude of the effects that the proton pump can generate.

\section{INSERT FIGURE 2}

In the DA-S setup, electrode 1 (Figures 1 and 2) is set at potential $\mathrm{V}_{1}+\mathrm{V}_{2}$; therefore, it can be considered as the effective anode to which the anions to be removed from the porous material will be forced to migrate. In the electrode 2, a lower potential $\mathrm{V}_{2}$ with respect to the cathode was established (Figures 1 and 2). In this way, this electrode was employed as a kind of bipolar electrode because it behaves as an anode with respect to electrode 3, located in the cathode, and hence it allows the mobilization of the anions present inside the porous material towards its vicinity. Furthermore, this electrode behaves as a cathode with respect to electrode 1, which forces the anions retained by poultice PA2 (located in the medium 2) to migrate towards the medium 1.

Titanium bars were used as electrodes due to its inertness with respect to the main reactions in the anode compartment (oxidation reactions). The main reactions occurring at both electrodes are:

Anodic electrochemical reactions:

$\mathrm{H}_{2} \mathrm{O} \rightarrow 1 / 2 \mathrm{O}_{2(\mathrm{~g})}+2 \mathrm{H}^{+}+2 \mathrm{e}^{-}$

$2 \mathrm{Cl}^{-} \rightarrow \mathrm{Cl}_{2(\mathrm{~g})}+2 \mathrm{e}^{-}$

Cathodic electrochemical reactions:

$$
2 \mathrm{H}_{2} \mathrm{O}+2 \mathrm{e}^{-} \rightarrow 2 \mathrm{OH}^{-}+\mathrm{H}_{2(\mathrm{~g})}
$$

According to previous studies [4-7, 15], it was necessary to place between the stone samples and the electrodes a material able to retain the ions forced to migrate to the vicinity of 
the respective electrode. Three different poultices made with different compounds were used for this purpose.

In the anodic compartment, medium 1 (corresponding to the DA-S, Figure 1) was filled with a poultice made of cellulose housing a citric acid/sodium citrate buffer solution, $\mathrm{pH} 6$ (here referred to as PA1). The efficacy of this buffer solution had been demonstrated in previous studies [5-6]. The weight cellulose/solution ratio employed was 1:7.6.

Cellulose was selected because of its high liquid storage capacity, which is due to its large pores with an access pore size diameter greater than $10 \mu \mathrm{m}$ [32-33]. As cellulose has a zero buffering capacity, the $\mathrm{H}^{+}$generated at electrode 1 , in contact with this poultice, are free to migrate to the vicinity of the electrode 2 , forming water. This effect corresponds to the "proton pump" which allows maintaining of the necessary water content for the proper functioning of the treatment.

The medium 2 (corresponding to the anode of both setups, Figure 1) was filled with a poultice made of kaolin, calcium carbonate, and the same buffer electrolyte mentioned above, following a weight ratio 1:2:1.3, respectively. We refer to this poultice as PA2.

In previous work, the addition of calcium carbonate to this poultice was effective at buffering the acidification of the anodic compartment $[4-7,10,15-16]$. The existence of the proton pump would allow buffering of the acidification in the vicinity of electrode 2 . However, if for any reason the $\mathrm{pH}$ of this medium becomes acid, the calcium carbonate would begin to decompose, decreasing the $\mathrm{pH}$ buffering, according to the Eq. 4 and 5:

$$
\begin{aligned}
& \mathrm{CaCO}_{3}+\mathrm{H}^{+} \rightarrow \mathrm{Ca}^{2+}+\mathrm{HCO}_{3}{ }^{-} \\
& \mathrm{HCO}_{3}{ }^{-}+\mathrm{OH}^{-} \rightarrow \mathrm{CO}_{2(\mathrm{~g})}+\mathrm{H}_{2} \mathrm{O}
\end{aligned}
$$

In the DA-S setup, the two media of the anodic compartment were separated using a cellulose filter. 
In the cathodic compartment a poultice made of kaolin and citrate/citric acid electrolyte buffered at $\mathrm{pH} 6$ was used (which we refer to as PC). The weight ratio kaolin/electrolyte employed was 1.6:1. Kaolin was selected by its ion exchange capacity, which allows the retention of the $\mathrm{OH}^{-}$generated at electrode 3 , thereby hindering its entrance into the system and increasing, in consequence, the efficiency of the treatment [5-7].

The stone prisms were positioned in the same direction (i.e., the face previously labelled with the numbers 1 and 2 was put in contact with the anodic compartment and the face labelled with the numbers 3 and 4 with the cathodic compartment). To reduce as much as possible the evaporation of water through the stone prisms, these were wrapped with plastic film. Furthermore, to hinder the evaporation through the holes of the cells, these were closed with rubber stoppers, allowing a minimal space for gases to escape.

\subsection{Operation of the DA-S setup}

As stated before, this DA-S setup contains two electrodes in the anodic compartment that work as a proton pump. The operation of the proton pump and its efficacy was evaluated under two different conditions, by establishing two different potential drops between the anode electrodes (DA-S2, 2V; DA-S3, 4V).

Taking into account the Faradays' law and the Eq. 6 and 7, the variation in concentration of protons, $\Delta\left[\mathrm{H}^{+}\right]$, at each electrode is related with the circulating charge and, therefore, with the current intensity.

At electrode 1: $\Delta\left[\mathrm{H}^{+}\right]=\mathrm{Q}_{1} / \mathrm{F} \omega=\mathrm{I}_{1} \mathrm{t} / \mathrm{F} \omega$

At electrode 2: $\Delta\left[\mathrm{H}^{+}\right]=\mathrm{Q}_{2} / \mathrm{F} \omega=\left(\mathrm{I}_{2}-\mathrm{I}_{1}\right) \mathrm{t} / \mathrm{F} \omega$

where Q corresponds to the electrical charge (in C) circulated; F is the Faraday constant (96485 $\mathrm{C} / \mathrm{mol}$ ), $\omega$ corresponds to the volume of the compartment, I corresponds to the circulating current (A), and $\mathrm{t}$ is the time elapsed (s) 
In this setup, it is expected that the higher potential difference established between the electrodes located at the anodic compartment $\left(\Delta \mathrm{V}_{1-2}\right)$ causes an increase in the intensity $\mathrm{I}_{1}$. This should lead to increased $\mathrm{H}^{+}$concentration in the vicinity of the electrode 1 , and decreased $\mathrm{H}^{+}$ concentration in the vicinity of electrode 2 .

Following this hypothesis, the following effects at electrode 2 located close to the porous material (Figure 1b) are expected:

- Generation of water molecules by neutralization $\left(\mathrm{H}_{3} \mathrm{O}^{+}+\mathrm{OH}^{-} \rightarrow 2 \mathrm{H}_{2} \mathrm{O}\right)$. These water molecules will keep, for a longer period, the moisture level needed for the flowing of electric current through the circuit.

- The buffering of $\mathrm{pH}$ in the vicinity of the electrode 2 . The drastic drop of the $\mathrm{pH}$ that occurs in the anodic compartment will occur only nearby the electrode located the furthest from the stone sample, which is the electrode 1. In the closest electrode (electrode 2), the generation of $\mathrm{OH}^{-}$will allow buffering of the acidic $\mathrm{pH}$ values.

- The reduction of the $\mathrm{H}^{+}$amount entering into the porous material.

The operation of the DA-S setup would be similar to the use of a bipolar electrode in the anode; the technique used in [34]. However, the DA-S setup presents the novelty of being able to regulate the potential difference established between the electrodes located in the anodic compartment, which allows for controlling the magnitude of the effects indicated above.

\subsection{Methods for evaluating the effectiveness}

Three tests were performed: T-S setup, DA-S2 setup and DA-S3 setup. The three tests lasted 11 days and were performed in triplicate using three stone prisms $(6 \times 6 \times 3 \mathrm{~cm})$ in each of the tests.

The potential drops of voltage between the electrodes (T-S: electrode 2 vs. electrode 3 ; DA-S: electrode 1 vs. electrode 2, electrode 1 vs. electrode 3 and electrode 2 vs. electrode 3 ) 
were recorded during the tests. For this, for $8 \mathrm{~h}$ per day, the potential drops were measured every $30 \mathrm{~min}$. Also, at the same time interval, the total intensity flowing through the stone prisms was calculated, considering the potential drop recorded in the $1 \mathrm{k} \Omega$ resistance (Figure 2). Moreover, the intensity that flows through the different media in DA-S was obtained directly from the power supplies.

At the end of each experiment, each stone prism was segmented into four pieces (indicated in blue in Figure 1) by hammer and chisel: pieces 1 and 2 correspond to the surfaces closest to the anode while pieces 3 and 4 correspond to those closest to the cathode. Poultices were segmented in three slices: a slice close to the anode (A), a medium slice (B), and a slice close to the cathode (C) (Figure 1).

In all these stone pieces and poultice slices, the following parameters were evaluated:

- Water content. This parameter was measured as the amount of water present in the material (stone or poultice) at the end of the test with respect to the dry weight obtained after drying the samples of rock and poultices at $105^{\circ} \mathrm{C}$, with the exception of the samples of the poultice PA1 (made of cellulose) that were dried at $50{ }^{\circ} \mathrm{C}$. The calculation of the water content allows us to assess the existence of electroosmotic process at the anodic compartment and to determine whether the water content inside the stone was sufficient to allow a homogeneous flow of the electric current.

- $\mathrm{pH}$, conductivity, and ion content of the aqueous extractions were obtained following the procedure above explained. These analyses were made in triplicate for all samples of rock and poultices. With the data obtained for each piece of the stone prisms, the desalination efficacy was calculated as the percentage of reduction of each ion (E\%ion), which is established following the expression used in [35].

$\mathrm{E} \%-$ ion $_{1-4}=100 \mathrm{x}\left(\right.$ Initial ion content $\mathrm{1}_{1-4}-$ Final ion content $\left.\mathrm{1}_{1-4}\right) /$ Initial ion content $_{1-4}$

\section{Results and discussion}




\subsection{Stone's properties}

Table 1 summarizes the main properties of the sandstone. The results show that this rock is of high porosity (in terms of accessible porosity to water and mercury). The difference between these parameters $(\approx 4 \%)$ indicates that this rock has a certain pore volume hardly accessible to water. Also, practically all the pores seem to fit within the range of the capillary pores, because the difference between the accessible porosity to water (13.24\%) and capillary porosity $(11.47 \%)$ is very low. Pore size distribution data were reported elsewhere [7]. This stone has two main pore families: Pore diameter between 1 and $10 \mu \mathrm{m}(74 \%)$ and pore diameter higher than $100 \mu \mathrm{m}(5 \%)$. The remaining porosity corresponds to pores that lie in the nanometer range. Thus, the majority of pores ( $80 \%$ of the volume) lie in the capillary range (i.e., access size diameter between $0.1-100 \mu \mathrm{m})$ [36].

\section{INSERT TABLE 1}

The surface charge of this stone was negative $(-24 \mathrm{mV})$. This fact represents hindered flow of anions but favoured transport of cations (with water) towards the cathode. This behaviour is typical of almost all the porous materials used in building constructions [16, 25-27, 37].

The initial ionic content of the prisms shows that 1) the nitrate and chloride content was higher than that of the rest of the ions, in accordance with the composition of the contaminating solution; and 2) the deviation between the ion content for the three reference stone prisms was very low, which demonstrates that this content is representative for the rest of the stone prisms.

\subsection{Intensity and resistance measurements}

Figure 3a shows that the resistance to current flow was greater for the stone prisms desalinated with the T-S setup than for the samples desalinated with the DA-S setups (DA-S2 and DA-S3). Between DA-S setups no difference was found regarding the resistance of the stone prisms. 
Regarding the flow of electric current (Figure 3b), it was seen that the current using the T-S poultice PA2 caused by the loss of water which prevented a proper electrode-poultice contact [1]. In fact, electrode 2 has to be shaken up periodically to improve the ionic contact, facilitating the current flow. Conversely, in the DA-S2 and DA-S3 setups, the current intensity flowing through the stone prisms was much higher than that of the T-S setup, also remaining constant during the tests. Shrinkage of the poultices at the anodes did not occur in the DA-S tests, which granted a good permanent contact between the electrodes 1 and 2 and the respective poultices.

Comparing DA-S setups, it was found that the electric current was higher in the DA-S3 test than in DA-S2. This result is expected considering that, for a similar resistance of the stone prisms and poultices (Fig. 3a), the application of a greater potential between anode and cathode allow a greater electric current to flow (Ohm's law: $\Delta \mathrm{V}=\mathrm{I} \times \mathrm{R}$ ).

\section{INSERT FIGURE 3}

\subsection{Water Content}

Table 2 shows the water content of the poultices and stone prisms after the tests. The results show differences in water content in poultices depending on the setup. Using the T-S setup, a greater loss of water at the cathode with respect to the anode occurred, while with both DA-S setups the results obtained were opposite (i.e., the greater loss of water occurred in the anodic compartment with respect to the cathode). The results of the DA-S were in concordance with previous research findings [16, 25-27], where an electroosmotic process was responsible for the hydration of the material located in the cathode compartment, as long as the surface charge of the material remains negative, such as in this case (Table 1).

The results achieved using the T-S setup could be related, as mentioned in [2, 4, 16, 25], to a decline of the electroosmotic process due to higher ion content in the stone prisms. 
Comparing both setups, the T-S setup leads to a greater reduction in water content in the was higher than $20 \%$ for the T-S setup in medium 2, while it ranged between $10 \%$ and $15 \%$ using the DA-S setup. The loss of water at the cathode using the T-S setup was around 23\%, while using the DA-S setup this parameter ranges between $8 \%$ and $13 \%$. These results suggest that the DA-S setup was able to maintain sufficient moisture content in the vicinity of the stone prisms due to the action of the proton pump, allowing the extraction process to proceed without interruption.

For the DA-S setups, regardless of the potential established (DA-S2 or DA-S3), the loss of water was higher in the PA1 poultice than in the PA2. This fact suggests a hydration process occurring during the treatment due to the establishment of an electroosmotic process. The generation of an electroosmotic process in clays is a well-known phenomenon [38]. At the cathode (PC poultice), the loss of water was still lower than at the anodes, which again suggests electroosmosis.

Comparing DA-S2 and DA-S3, it was noted that, under higher potential (DA-S3), higher water decreasing occurs in medium 1, in accordance with the electroosmotic process caused by the proton pump. Moreover, it was noticed that the water contents of medium 2 and the cathode are more similar under the DA-S3 condition than DA-S2. This fact suggests that the electroosmotic processes established in the medium 2 and in the cathode were similar, so that the drying of both compartments occurred at similar rates.

Regarding the water content in the stone prisms, there was a significant difference between the setups evaluated. With respect to the T-S setup, the DA-S2 setup caused an increase in the water content of about $24 \%$, and the DA-S3 setup caused an increase of about 43\%. These results showed that the proton pump generated with the DA-S setup allowed an increase in the water content inside the material. 
Therefore, as indicated in the hypothesis, the DA-S setup allowed us to solve the problem related to the water loss in the anode compartment, thereby moisturizing the anode material located close to the stone.

\section{4. pH measurements}

Figure 4 shows the different $\mathrm{pH}$ values measured in the aqueous extractions of the different slices (A, B and C) of the poultices that fill each of the cells (PA1 and PA2 at the anode and PC at the cathode), as well as the $\mathrm{pH}$ measured on the faces of the stone prisms close to the anode and cathode.

Regarding the T-S setup, the $\mathrm{pH}$ values of medium 2 were slightly basic. These results show, as expected based on other studies $[5-7,15]$, that the amount of $\mathrm{CaCO}_{3}$ that was added to the PA2 poultice was sufficient to buffer the acidification processes. The $\mathrm{pH}$ values reached ranged from 10 to 11 at the cathode, values characteristic of this medium. The $\mathrm{pH}$ values of the stone prisms were high (ranged from 9 to 11 approximately), especially in the surface closest to the anode. This result could be related to the amount of $\mathrm{Ca}^{2+}$ ions released during the $\mathrm{pH}$ buffering. $\mathrm{Ca}^{2+}$ can enter into the rock during treatment, react with the atmospheric $\mathrm{CO}_{2(\mathrm{~g})}$ after the treatment, during drying, and, therefore, carbonation processes can generate $\mathrm{CaCO}_{3}$ [39].

\section{INSERT FIGURE 4}

Regarding the DA-S setup, the $\mathrm{pH}$ values reached in the medium 1 ranged from 2.5 to 3.7, indicating heavy acidification. Using the DA-S3 setup, an increase in the acidification process took place, due to the higher current $I_{1}$ between electrodes 1 and 2 (see Eq. 6 and Fig. 3). In the medium 2, using the DA-S2 setup, the $\mathrm{pH}$ values in the slices $\mathrm{A}$ and $\mathrm{B}$ were similar to those reached with the T-S setup. In the slice $\mathrm{C}$, in which electrode 2 was placed, the $\mathrm{pH}$ values became more basic (8.75) due to the generation of $\mathrm{OH}^{-}$at the surface of the electrode, which helped to buffer pH (see Eq. 7). Using the DA-S3 setup, the results show a similar trend, 
although the $\mathrm{pH}$ values reached were higher than those with DA-S2, especially at the surface of the electrode 2.

At the cathode, the $\mathrm{pH}$ values reached using the DA-S setups ranged from 11.2 to 11.6, which were on average more basic than those obtained using T-S setup. However, taking into account the deviation of the results obtained after the application of the T-S in slices B and C, the differences are not significant. The reason for this slightly higher $\mathrm{pH}$ could be related to a decreased releasing of calcium ions from the PA2 poultice during the $\mathrm{pH}$ buffering process or to increased $\mathrm{OH}^{-}$retention by the PC poultice. The calcium released can flow from the anode to the cathode, where it will react with the $\mathrm{OH}^{-}$ions forming $\mathrm{Ca}(\mathrm{OH})_{2}$ precipitate [4]. This process, the fixation of the $\mathrm{OH}^{-}$with $\mathrm{Ca}$ ions through calcium hydroxide production, is a normal aspect of the T-S setup.

Using the DA-S setup, the proton pump favours the buffering of $\mathrm{pH}$ at the anode, reducing $\mathrm{CaCO}_{3}$ dissolution from the PA2 poultice and the subsequent calcium release. Therefore, the $\mathrm{pH}$ values measured were higher in the poultice PA2, especially with the application of the DA-S3 setup, due to the higher working intensity of the proton pump. Therefore, using the DA-S setup, it is possible to reduce the amount of $\mathrm{CaCO}_{3}$ used in the preparation of the PA2 poultice. The reduction depends on the potentials applied to each of the electrodes because the buffering capacity of the setup will increase with $\Delta \mathrm{V}_{1-2}$.

The $\mathrm{pH}$ values reached in the stones desalinated using DA-S setups were different as a function of the voltage applied to electrode 1 . With the DA-S2, the $\mathrm{pH}$ values were, on average, higher than those reached with the DA-S3. Using the DA-S2, the pH values reached were lower on the surface closest to the anode than those reached on the surface closest to the cathode. Using the DA-S3, $\mathrm{pH}$ values were similar on both rock surfaces (being in some cases a bit higher on the surface near the cathode), and were close to the characteristic $\mathrm{pH}$ of the untreated stone $(7.15 \pm 0.62)$. 
The results obtained with both DA-S setups confirm that the proton pump allows for

\subsection{Conductivity measurements}

Figure 5 shows the conductivity values of aqueous extractions of the slices of the poultices and the stone pieces. These values give an idea of the ionic content of the media analysed; the higher the conductivity, the greater the ionic content.

The conductivity reached in the stone pieces, both in the anode and in the cathode, was always higher with the T-S setup than with the DA-S setups. These results are indicative that the ionic content in the stone prisms desalinated by this setup is higher than in those desalinated with DA-S setups.

Comparing the DA-S setups, the trend is different in the anode and in the cathode. In the surfaces closest to the anode, the lowest conductivity values are obtained with the DA-S2 setup and in the surfaces closest to the cathode, with the DA-S3 setup.

At the cathode, the conductivity values were higher, in most cases, using the T-S setup than using any of the DA-S setups. This might be due to the higher amount of $\mathrm{Ca}^{2+}$ ions released in the T-S setup, since the buffering of the $\mathrm{pH}$ in the anode using this setup is exclusively due to the action of the PA2 poultice. The lowest conductivity in this compartment was achieved using the DA-S3 setup. 
In medium 2, the highest conductivity values were achieved with the T-S setup and with the DA-S3 setup, and we detected no significant differences between the setups. In medium 1 , the highest conductivity was reached using the DA-S3 setup, which could indicate a greater mobilization of anions towards this medium.

\section{INSERT FIGURE 5}

\subsection{Ion content in the poultice}

Table 3 shows the total average amount of the ions retained in each of the compartments (anode and cathode) and also the ion content retained in each of the media that form the anodic compartment (medium 1 and medium 2).

The results in Table 3 show that the ion content in the anode is higher than in the cathode. Moreover, the ion content is higher in the DA-S setups anodes than in the T-S setup, especially of the DA-S3. These facts are true for all ions except for $\mathrm{Na}^{+}$. The sodium content is higher at the cathode than at the anode; and at the anode, it is higher in the T-S setup than in the DA-S setups. A similar behaviour is observed for the anions.

Regarding the chloride ion, the results show that the DA-S setup allows extracting higher amount of chloride than the T-S setup (Table 3), mainly with the DA-S3 setup. This is the expected result considering the higher current recorded.

Analysing each of the anode media that form the different setups (Table 3), it was found that the amount of chloride retained in medium 2, the one closest to the rock, was slightly higher when the T-S setup was used. Using the DA-S setup, part of the chloride extracted from the stone was mobilized towards medium 1 , in which the electrode with the highest potential was located. This mobilization was greater using the DA-S3 setup. Concerning the cathode, the quantity of chloride was higher when a T-S setup was used, followed by the DA-S2 setup. The 
existence of this ion in this compartment is due to the establishment of diffusive and advective processes in the PC poultice.

The results obtained by analysing the nitrate and sulphate ions were similar to those obtained by analysing the chloride ion (i.e., higher extraction in the anode compartment with DA-S setup than T-S setup, mainly with DA-S3 setup). In this DA-S3 configuration, the highest mobilization of both ions towards the medium 1 was obtained. At the cathode, the highest amount retained was obtained with the T-S setup and the lowest with the DA-S3 setup, especially for sulphate.

These results suggest that the drying of the anodic compartment, when the T-S setup was used hinders the process of forced ion migration under the influence of the electric field. This fact facilitates the extraction of anions present in the stone via advection and diffusion processes [40]. This would explain why using the T-S setup the anion content at the cathode is higher than that obtained using the DA-S setup (especially the sulphate content). On the contrary, using the DA-S setup, which reduces the drying rate of the anode's poultice due to the action of the proton pump, the migration process of these anions under the influence of the electric field can be held for a longer time.

In the case of the cations, two different behaviours are observed for sodium and calcium. The sodium content is higher than the calcium content, and it is also higher at the cathode than at the anode. This might be because sodium is present in the electrolyte employed to prepare each of the poultices. Moreover, migration pushes the cations towards the cathode. In the cathode, the sodium content was similar in the three setups while, in the anode, the content was higher in the T-S setup and lower in the DA-S setups. This fact could be related to a different migration ability of this ion in each of the setups.

Concerning the calcium content, it is higher at the anode because calcium is part of the PA2 composition. Moreover, the calcium content at the anode is higher in the DA-S setups, especially in the DA-S3 while at the cathode the highest content of calcium is obtained for the 
T-S setup. These results point directly to the dissolution of $\mathrm{CaCO}_{3}$ in poultice PA2 during the $\mathrm{pH}$ buffering at the anode, and the subsequent migration of calcium ions released from the anode to the cathode.

The higher calcium content present in the anode of the DA-S setup, especially in the DA-S3, demonstrates that the proton pump allows $\mathrm{pH}$ buffering through the action of the electric field, thus reducing the amount of calcium released compared to if the poultice were performing the buffering function.

Using the DA-S setups, the release of calcium occurs mainly in the contact zone between poultices PA1 and PA2, which explains the presence of calcium ions in medium 1 . The higher calcium content in medium 2 of the DA-S3 can be explained by the fact that the buffering capacity of the $\mathrm{pH}$ in this setup is higher than in the DA-S2 (this is consistent with the discussion in section 3.4). In the T-S setup, the buffering function is performed by the calcium carbonate present in the PA2 poultice (as seen in Eqs. 4 and 5). During this buffering process, part of the calcium is released and migrates towards the cathode. Thus, the T-S setup makes the calcium content increased in the cathode and decreased in the anode.

\subsection{Ion content in the stone}

Figure 6 shows the desalination efficacy percentages (E\%-ion) of the anion extraction (chloride, nitrate and sulfate) for the four sampling points considered in the rock (two of the anode and two of the cathode).

In general, regardless of the anion, extraction rates in most cases were higher in the DAS setups. This is because the desalination process in the DA-S setups worked through the whole period thanks to the proton pump, while in the T-S setup the drying of the materials (poultices and rock) discontinued the process. With the T-S setup enrichments were produced which were manifested with negative percentages of efficacy and in general the dispersion of the values obtained with this test was much higher. 
Regarding the results for the DA-S setups, differences between the anode and the

cathode for the three ions were found. With respect to chloride and nitrate, the average percentages of efficacy achieved using the DA-S2 setup were practically constant (approximately 40\%) throughout the entire sample. With the DA-S3 setup, the percentages of efficacy were lower in the areas closer to the anode (approximately 30\%) and higher in the areas closer to the cathode (approximately $50 \%$ for chloride and above $60 \%$ for nitrate), surpassing in most cases in this zone the percentage of extraction achieved with the DA-S2. This indicates that the DA-S3 is more efficient because it allows a greater mobilization of the anions (i.e. an extraction from the cathode towards the anode and consequently a higher accumulation of both ions at the anode with respect to the DA-S2). This higher accumulation would not have occurred if the test had not been stopped.

\section{INSERT FIGURE 6}

Using the T-S setup, sulfate enrichments were much higher than those of $\mathrm{Cl}^{-}$and the $\mathrm{NO}_{3}{ }^{-}$, especially in the zones closer to the anode. The sulfate enrichments are related to the lower mobility of this ion, especially when there are more mobile ions in the media, as indicated in [7]. Higher sulfate extraction efficiencies are reached (slightly higher than 60\%) with the DAS2 than those achieved for chloride and nitrate; this occurs in practically the whole rock, with the exception of level 3. The extraction percentages of sulfate obtained with DA-S3 are lower than those of chloride and nitrate, but they show a similar tendency, i.e., higher at the cathode (30-50\%) and lower at the anode (being, at some level, negative). This fact, together with the contents of salts retained in the anode (Table 3), shows that DA-S3 is still producing a mobilization of the sulfate ions from the cathode to the anode, a mobilization much more effective than that obtained by the DA-S2.

Figure 7 shows the percentage of efficacy in the extraction of calcium and sodium for the four sampling points of the rock (two of the anode and two of the cathode). In general, for both calcium and sodium, extraction efficiencies were higher in the DA-S setups than in the T-S 
setup. Again, the negative influence of the drying of the materials (poultices and rock) with the T-S setup in the mobilization of ions is evident.

\section{INSERT FIGURE 7}

Regarding calcium ion, the highest efficacy was achieved with the DA-S3 setup because, by operating the proton pump with greater intensity, the input of calcium into the rock is lower. Calcium comes from the dissolution of $\mathrm{CaCO}_{3}$ of the PA2 poultice. It is necessary to take into account that according to previous results $[5,39]$, the calcium entering the stone can precipitate in the form of $\mathrm{CaCO}_{3}$ and, as a consequence, can collapse some percolating pores. Therefore, the application of the DA-S setups allows for control of the possible structural changes occurring in the rock.

With respect to sodium (Figure $7 \mathrm{~b}$ ), the percentages of efficacy achieved with the application of the DA-S2 and DA-S3 setups were very similar in almost all of the deptht levels sampled. These percentages were higher than those achieved with the T-S setup, where high enrichments were seen.

In general terms, the DA-S setups and TS setup differ in the content of salts remaining in the rock, the amount of salts that are extracted to the poultices (Table 3), the intensity circulating during the 11 days of treatment (Figure 3b), and the water content in both poultices and rocks (Table 2). These differences confirm that the DA-S setups have been operating correctly during the 11 days of the test and could even run for longer, which would increase the differences found with the T-S setup.

\section{Conclusions}

The main conclusions derived from this study are:

1) The design of the DA-S setup is adequate to make a proton pump work at the anode. 
2) The proton pump of the DA-S setup allows an electro-osmotic process at the anode, bringing electrodes and the poultices.

3) The proton pump of the DA-S setup gives to the system a self-buffering capacity of $\mathrm{pH}$ in the anodic compartment since the system can generate at the relative anode $\mathrm{OH}^{-}$ions, which can counteract the acidification usually occurring at the anode.

4) The proton pump of the DA-S setup allows increasing of the effectiveness of the conventional desalination treatment. This is because the operation of the pump hinders the entrance of the $\mathrm{H}^{+}$ions into the porous material that reduces the mobilization of the ions to be extracted.

5) All of these effects of the proton pump are increased when the potential between the electrodes located in the anodic compartment increases. Thus, this parameter which is easily adjustable.

6) The proton pump buffering effect decreases the calcium released by decomposition of the $\mathrm{CaCO}_{3}$ of the PA2 poultice. The lower release of calcium decreases the probability of blocking percolating pores in the rock. However, the lower release of $\mathrm{Ca}^{2+}$ ions causes a disadvantage with respect to the $\mathrm{pH}$ of the cathode: the lower the amount of calcium available, the less the ability to neutralize $\mathrm{OH}^{-}$. So, although the proton pump substantially improves the performance of a traditional setup, it would be advisable to conduct a study focused on the analysis of whether an improved cathodic compartment (developed following the same theoretical principles) could solve this problem.

Conflict of Interest: The authors declare that they have no conflicts of interest.

\section{References}


[1] Ottosen, L.M.; Rörig-Dalgaard, I. (2007) Electrokinetic removal of $\mathrm{Ca}\left(\mathrm{NO}_{3}\right)_{2}$ from bricks to avoid salt-induced decay. Electrochimica Acta; 52:3454-3463.

[2] Ottosen, L.M. and Rörig-Dalgaard, I. (2009), Desalination of a brick by application of an electric DC field. (2009) Materials and Structures. vol. 42, issue 7, p. 961-971.

[3] Ottosen, L.M. and Christensen, I.V. (2012). Electrokinetic desalination of sandstones for $\mathrm{NaCl}$ removal - Test of different clay poultices at the electrodes. (2012) Electrochimica Acta. vol. 86, p. 192-202. DOI: 10.1016/j.electacta.2012.06.005.

[4] Ottosen, L.M.; Ferreira, C.M.D.; Christensen, I.V. (2010). Electrokinetic desalination of glazed ceramic tiles. J. Appl. Electrochem. 40:1161-1171.

[5] Feijoo, J.; Ottosen, L.M.; Pozo-Antonio, I. Influence of the properties of granite and sandstone in the desalination process by electrokinetic technique. Electrochimica Acta 2015; 181: $280-287$.

[6] Feijoo, J.; Nóvoa, X.R.; Rivas, T.; Mosquera, M.J.; Taboada, J.; Montojo, C. and Carrera, F. (2012). Granite desalination using electromigration. Influence of type of granite and saline contaminant. Journal of Cultural Heritage. Volume 14, issue 5, pp. 365-376.

[7] Feijoo, J.; Matyscak, O.; Ottosen, L.M.; Rivas, T.; Nóvoa, X.R. (2017). Electrokinetic desalination of protruded areas of stone avoiding the direct contact with electrodes. Mater Struct. 50:82 doi:10.1617/s11527-016-0946-x

[8] Matyščák, O.; Ottosen, L.M. and Rörig-Dalgaard, I. (2014), Desalination of salt damaged Obernkirchen sandstone by an applied DC, Construction and Building Materials 71 (2014) 561569, Elsevier.

[9] Ottosen, L.M.; Christensen, I.V.; Rörig-Dalgaard, I. (2012). Electrochemical desalination of salt infected limestone masonry of a historic warehouse. Structural Faults and Repair, Edinburgh 2012. Proceedings. 
[10] Ottosen, L.M.; Rörig-Dalgaard, I.; Villumsen, A. (2008). Electrochemical removal of salts from masonry- Experiences from pilot scale. Salt Weathering on Buildings and Stone Sculptures, in: Proceedings from the International Conference 22-24 October 2008, Technical University of Denmark, The National Museum Copenhagen, Denmark.

[11] Ottosen, L.M.; Pedersen, A.J.; Rörig-Dalgaard, I. (2007). Salt-related problems in brick masonry and electrokinetic removal of salts. Journal of Building Appraisal VOL.3 NO.3 pp $181-194$.

[12] Feijoo, J.; Rivas, T.; Nóvoa, X.R.; de Rosario, I. \& Otero, J. (2017). In situ desalination of a granitic column by the electrokinetic method. International Journal of Architectural Heritage, DOI: $10.1080 / 15583058.2017 .1370509$

[13] Auras, M. (2008). Poultices and mortars for salt contaminated masonry and stone objects. Proc. International Conference Salt weathering on buildings and stone sculptures. 22-24 October 2008. The National Museum Copenhagen, Denmark. Technical University of Denmark.

[14] Kamran, K.; Soestbergen, M. van; Huinink, H.P. \& Pel, L. (2012). Inhibition of electrokinetic ion transport in porous materials due to potential drops induced by electrolysis. Electrochimica Acta, 78, 229-235.

[15] Rörig-Dalgaard, I. (2012). Development of a poultice for electrochemical desalination of porous buildings materials: desalination effect and $\mathrm{pH}$ changes. Materials and Structures DOI $10.1617 / \mathrm{s} 11527-012-9946-7$.

[16] Ottosen, L.M.; Rörig-Dalgaard. (2006). Drying brick masonry by electroosmosis. Proceedings from 7th International Masonry Conference, London, UK, 2006, 31-41.

[17] Liu, Y.; Shi, X. (2012). Ionic transport in cementations materials under an externally applied electric field: finite element modeling. Cons. Build. Mat. 27 450-460. 
[18] Li, C.; Man, H.; Song, C.; Gao, W. (2013). Fracture analysis of piezoelectric materials using the scaled boundary finite element method. Engineering Fracture Mechanics. Volume 97, Pages 52-71.

[19] Zhang, T.Y.; Gao, C.F. (2004). Fracture behaviors of piezoelectric materials. Theor. Appl. Fract. Mech., 41, pp. 339-379.

[20] Xie, T.; Fan, C.Y.; Liu, H.T.; Zhang, T.Y. (2014) Effect of electrostatic tractions on the fracture behavior of a piezoelectric material under mechanical and/or electric loading. Theor. Appl. Fract. Mech., 69, pp.6-16.

[21] Bertolini, L.; Bolzoni, F.; Elsener, B.; Pedeferri, P.; Andrade, C. (1996). La realcalinización y la extracción electroquímica de los cloruros en las construcciones de hormigón armado. Materiales de Construcción. Vol 46 n 244, octubre/noviembre/diciembre 1996.

[22] Castellote, M.; Andrade, C.; Alonso, C. (2000). Electrochemical removal of chlorides Modelling of the extraction, resulting profiles and determination of the efficient time of treatment. Cement and Concrete Research 30; pp. 615-621.

[23] Kamran, K.; Pel, L.; Sawdy, A.; Huinink, H.; Kopinga, K. (2012).Desalination of porous building materials by electrokinetics: an NMR study. Materials and Structures 45; 297-308.

[24] Tritthart, J. (2000). Electrochemical chloride removal. A case study and laboratoty tests. Page C L. Bamforth P B, Figg J W (eds) Proc. Fourth Int. Symp. On Corrosion of Reinforcement in Concrete Construction, Society of Chemical Industry Cambridge 433-47.

[25] Bertolini, L.; Coppola, L.; Gastaldi, M.; Redaelli, E. (2009). Electroosmotic transport in porous construction materials and dehumidification of masonry. Construction and Building materials 23 pp. $254-263$.

[26] Franzoni, E. (2014). Rising damp removal from historical masonries: A still open challenge. Construction and Building Materials 54 (2014) 123-136. 
[27] Franzoni, E.; Bandini, S.; Graziani, G. (2014). Rising moisture, salts and electrokinetic effects in ancient masonries: From laboratory testing to on-site monitoring. Journal of Cultural Heritage 15 pp. 112-120.

[28] RILEM (Réunion Internationale des Laboratoires d'Essais et de Recherche sur les Matériaux et les Constructions) 1980a. Commission 25 PEM. Protection et Erosion des Monuments. Recommandations provisoires. Essais recommandés pour mesurer l'altération des pierres et évaluer l'efficacité des méthodes de traitement. Test No. II. 1: Open porosity and Test II. 2: Bulk and real densities.

[29] Benavente, D. (2002). Modelización y estimación de la durabilidad de materiales pétreos porosos frente a la cristalización de sales. Tesis doctoral 2002 Universidad de Alicante.

[30] ICR-CNR- Instituto Centrale do restauro- Commisione Normal. 1985. Doc. NORMAL 11/85. Assorbimento d'acqua per capilaritá. Coefficiente di assorbimento capillare.

[31] Unhruh, J. (2001). A revised endpoint for ceramics desalination at the archaeological site of Gordon-Turkey. Studies in Conservation 46, pp 81-92.

[32] Bourgès, A.; Vergès-Belmin, V. (2008). Comparison and optimization of five desalination systems on inner walls of Saint Philibert church in Dijon, France, Salt Weathering on Buildings and Stone Sculptures, in: Proceedings from the International Conference 22-24 October 2008, Technical University of Denmark, The National Museum Copenhagen, Denmark, pp. 29-41.

[33] Lubelli, B.; van-Hees, R.P.J. (2010). Desalination of masonry structures: Fine tuning of pore size distribution of poultices to substrate properties. Journal of Cultural Heritage 11 10-18.

[34] Golder, A.K.; Samanta, A.N.; Ray S. (2007). Removal of $\mathrm{Cr}^{3+}$ by electrocoagulation with multiple electrodes: Bipolar and monopolar configurations. Journal of Hazardous Materials 141 pp. 653-661.

[35] Lubelli, B.; van Hees, R.P.J.; De Clercq, H. (2011). Fine tuning of desalination poultices: try-outs in practice SWBSS. Limassol. Cyprus. 
[36] Winkler, E.M. (1997). Stone in Architecture: Properties, Durability, 3rd ed. SpringerVerlag, Berlin, 309p.

[37] Feijoo, J.; Ottosen, L.M.; Nóvoa, X.R.; Rivas, T.; de Rosario, I. (2017). An improved electrokinetic method to consolidate porous materials. Materials and Structures (2017) 50:186.

[38] Grundl, T.; Michalski, P. (1996). Electrosmotically driven water flow in sediments. Water Res 30(4):811-818.

[39] Paz-García, J.M.; Johannesson, B.; Ottosen, L.M.; Ribeiro, A.B.; Rodríguez-Maroto, J.M. (2013). Simulation-based analysis of the differences in the removal rate of chlorides nitrates and sulfates by electrokinetic desalination treatments. Electrochimica Acta 89 436-444.

[40] Pel, L.; Sawdy, A.; Voronina, V. (2010). Physical principles and efficiency of salt extraction by poulticing. Journal of Cultural Heritage 11 (2010) 59-67. 


\section{FIGURE CAPTIONS}

Figure 1. Scheme of the two assemblies evaluated in this research (Traditional setup (T-S, a); Double Anode setup (DA-S, b)) and electrokinetic phenomena that take place in each of the tested setups. The different slices in which the poultices and the stone samples were divided for their analyses are also shown.

Figure 2. Scheme of the electric circuit of the two setups Traditional setup (T-S) and Double Anode setup (DA-S). The solid line corresponds to the electric circuit used in the T-S setup. The dashed lines correspond to the addition necessary to apply the DA-S setup. The scheme contains the electrodes and the variable resistance (poultices, stone and a calibrated resistance of $1 \mathrm{k} \Omega$ employed for accurate current measurements). All of the elements are connected in series.

Figure 3. a) Average measurements of the resistance (in $\mathrm{k} \Omega$ ); and b) the total current intensity (in $\mathrm{mA}$ ) that flows through the samples during the 11 days of the tests.

Figure 4. $\mathrm{pH}$ average measurements reached in the different parts of the setup (poultice slices and stones pieces).

Figure 5. The average conductivity measurements reached in the different parts of the setup (poultice slices and stone pieces).

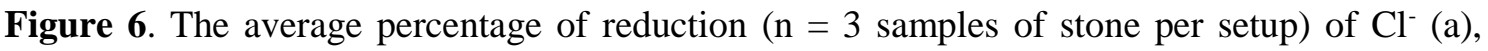
$\mathrm{NO}_{3}^{-}$(b) and $\mathrm{SO}_{4}{ }^{2-}(\mathrm{c})$ in the different pieces of the stone.

Figure 7. The average percentage of reduction ( $n=3$ samples of stone per setup) of $\mathrm{Ca}^{2+}$ (a) and $\mathrm{Na}^{+}(\mathrm{b})$ in the different pieces of the stone. 
a) $\mathrm{T}-\mathrm{S}$

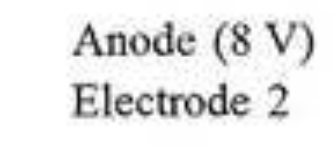

Cathode

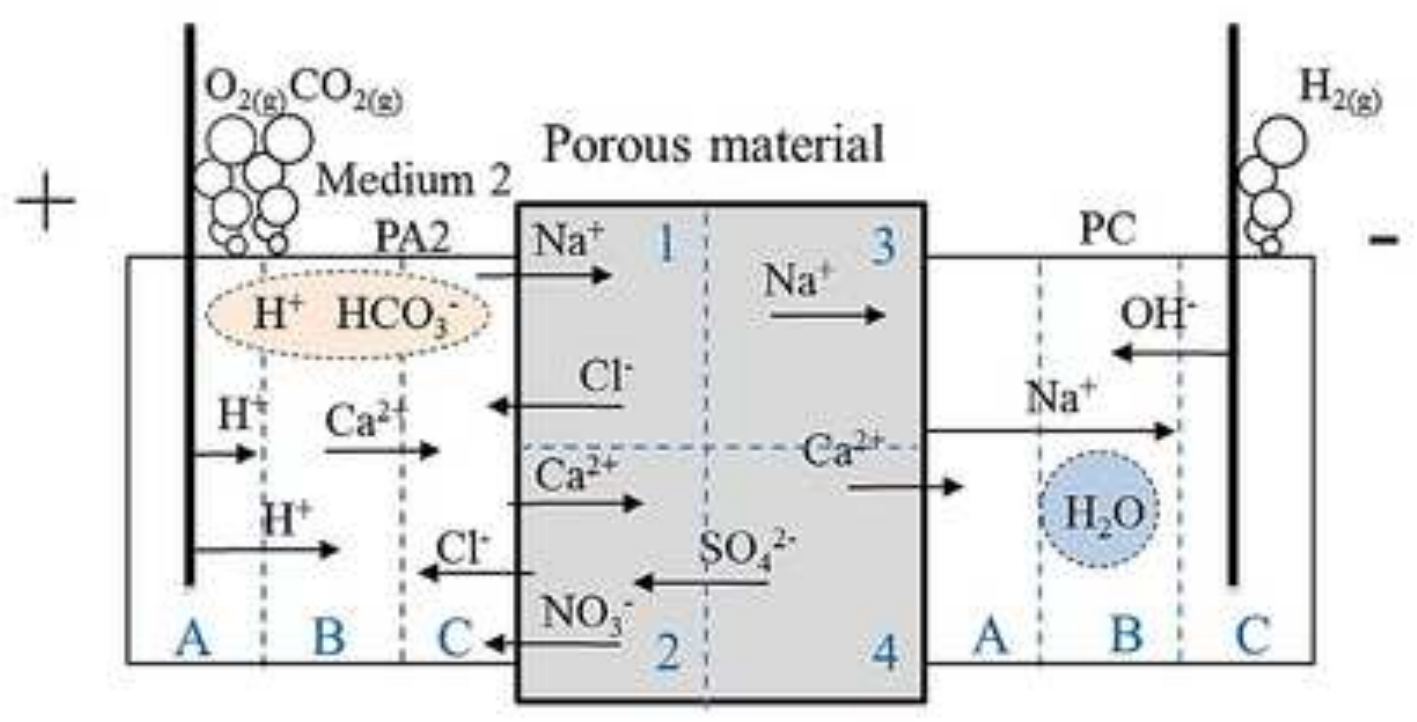

b) DA-S

Anode (2 V/4V)

Electrode 1

\section{Anode (8 V)}

Electrode 2

\section{Cathode}

Electrode 3

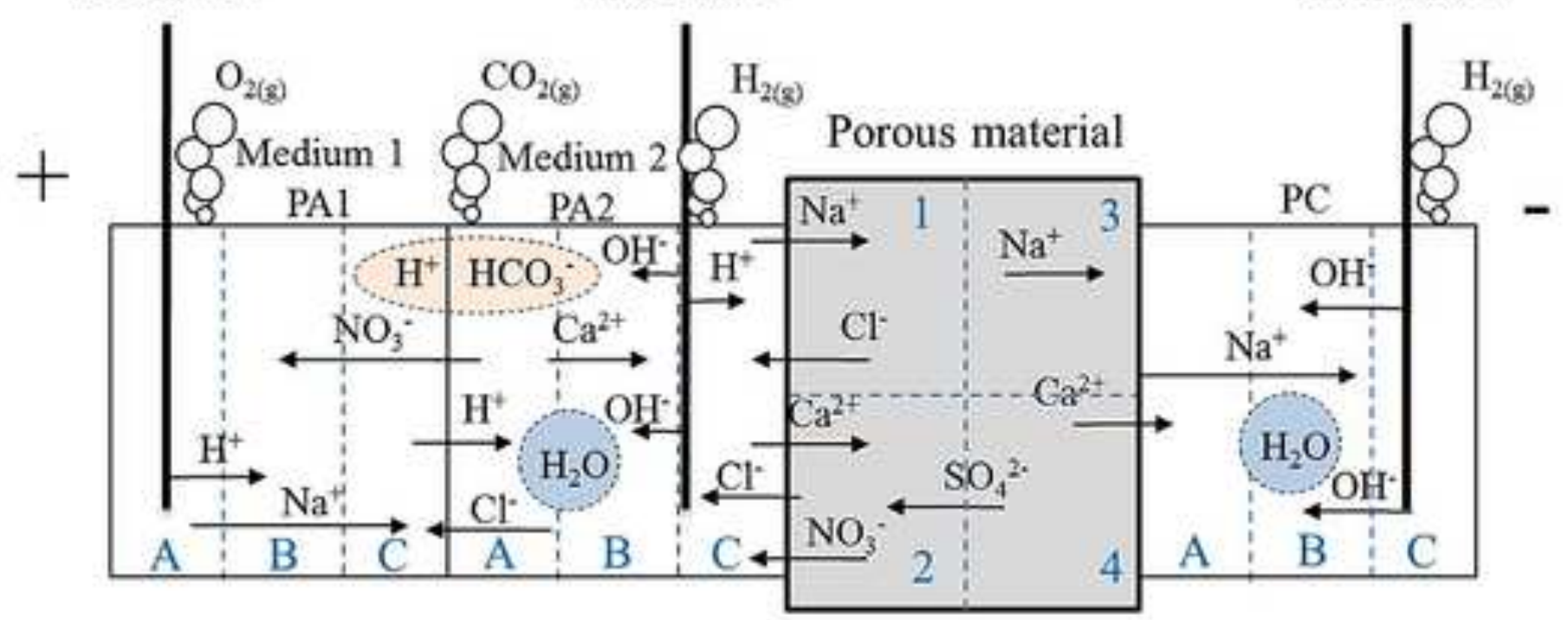




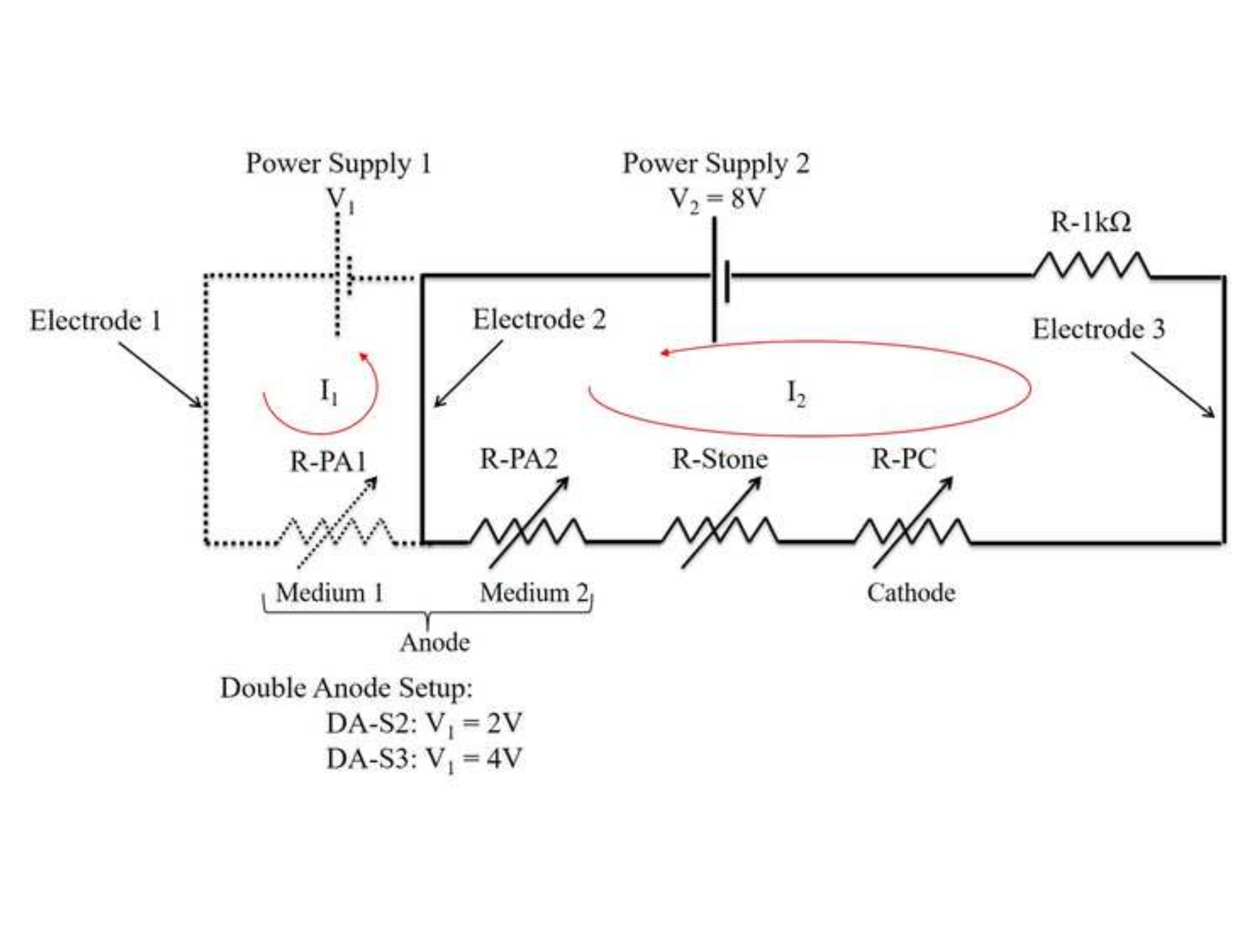




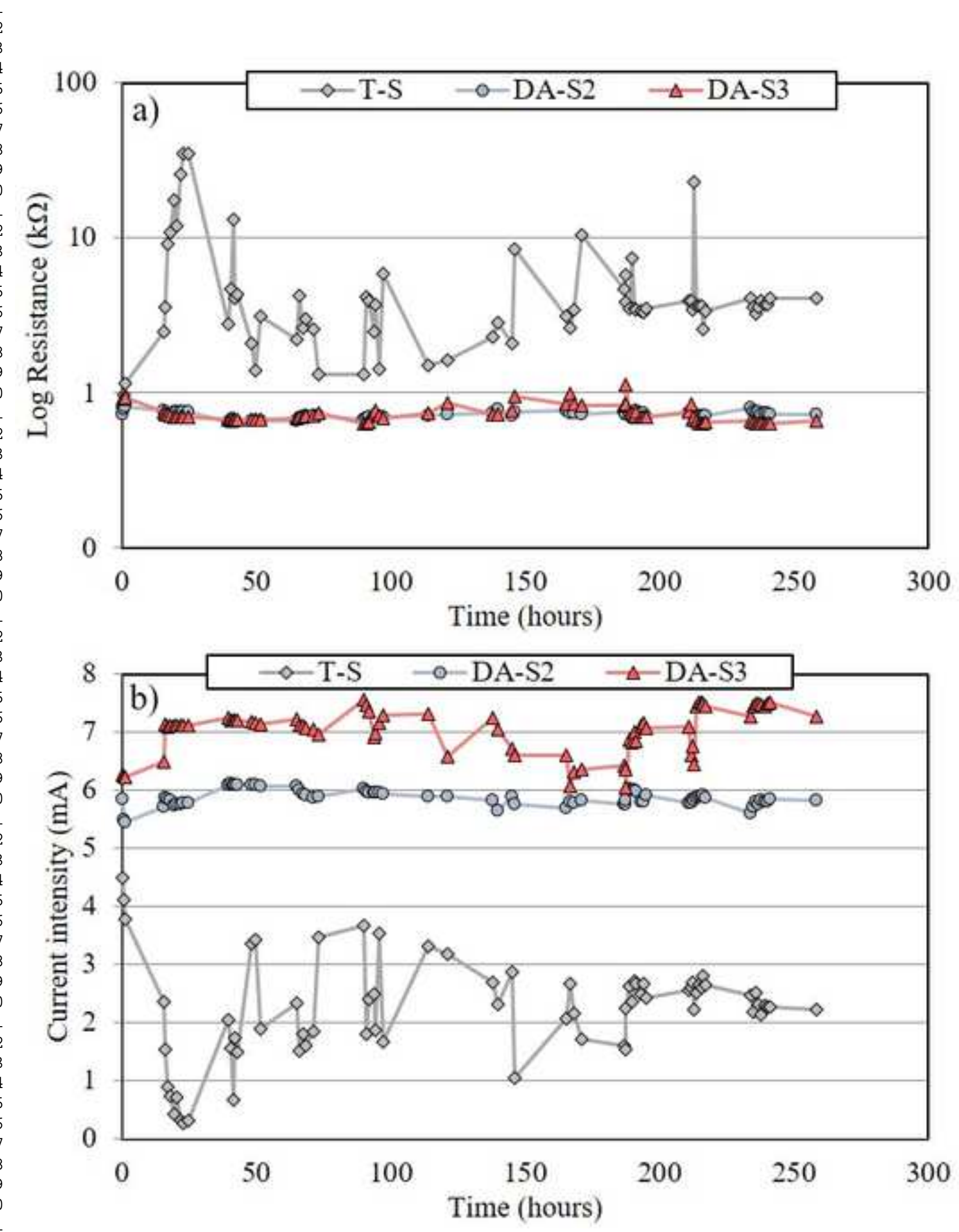




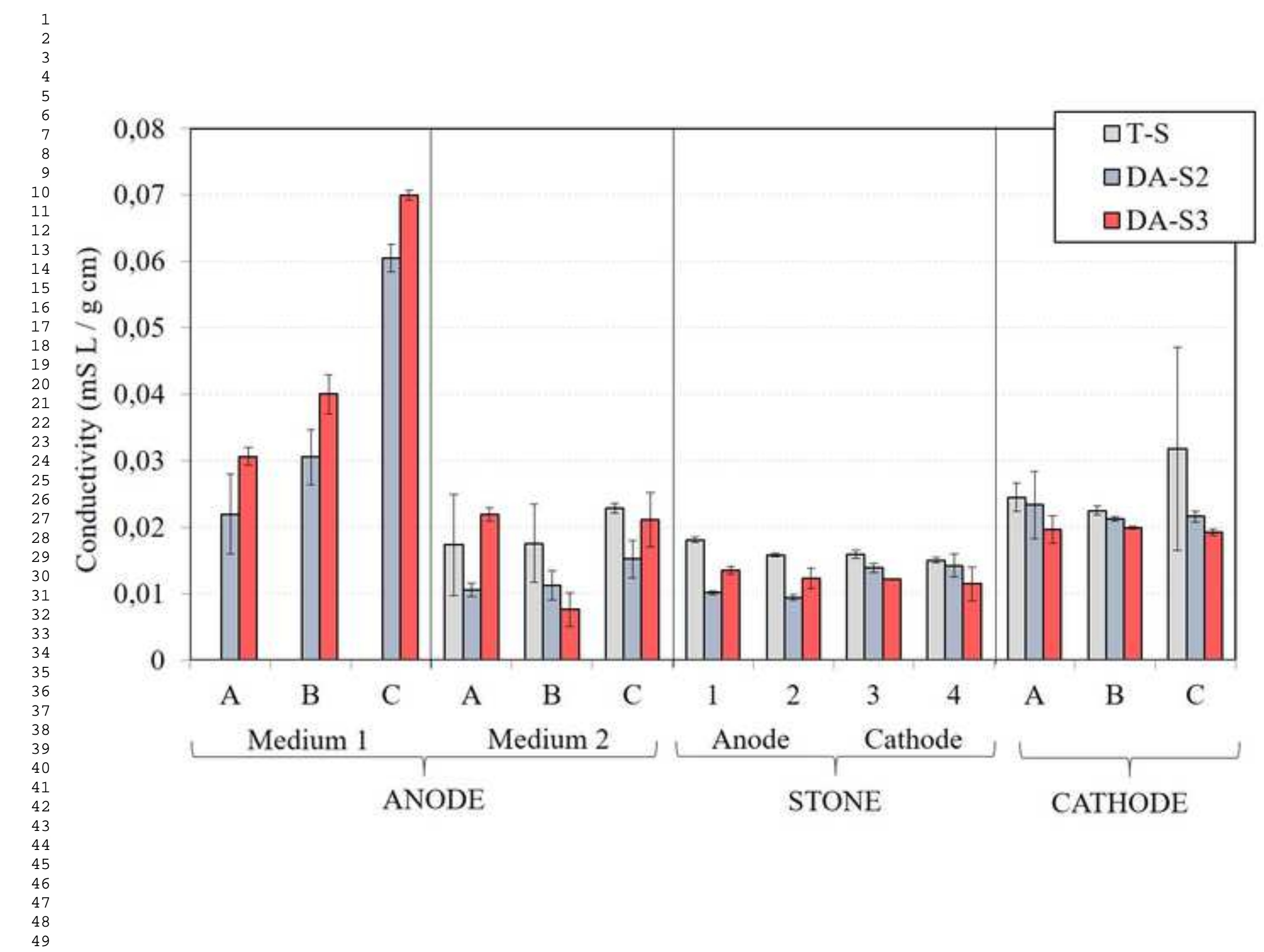


1

3

4

5

6

7

8

9

10

11

12

13

14

15

16

17

18

19

20

21

22

23

24

25

26
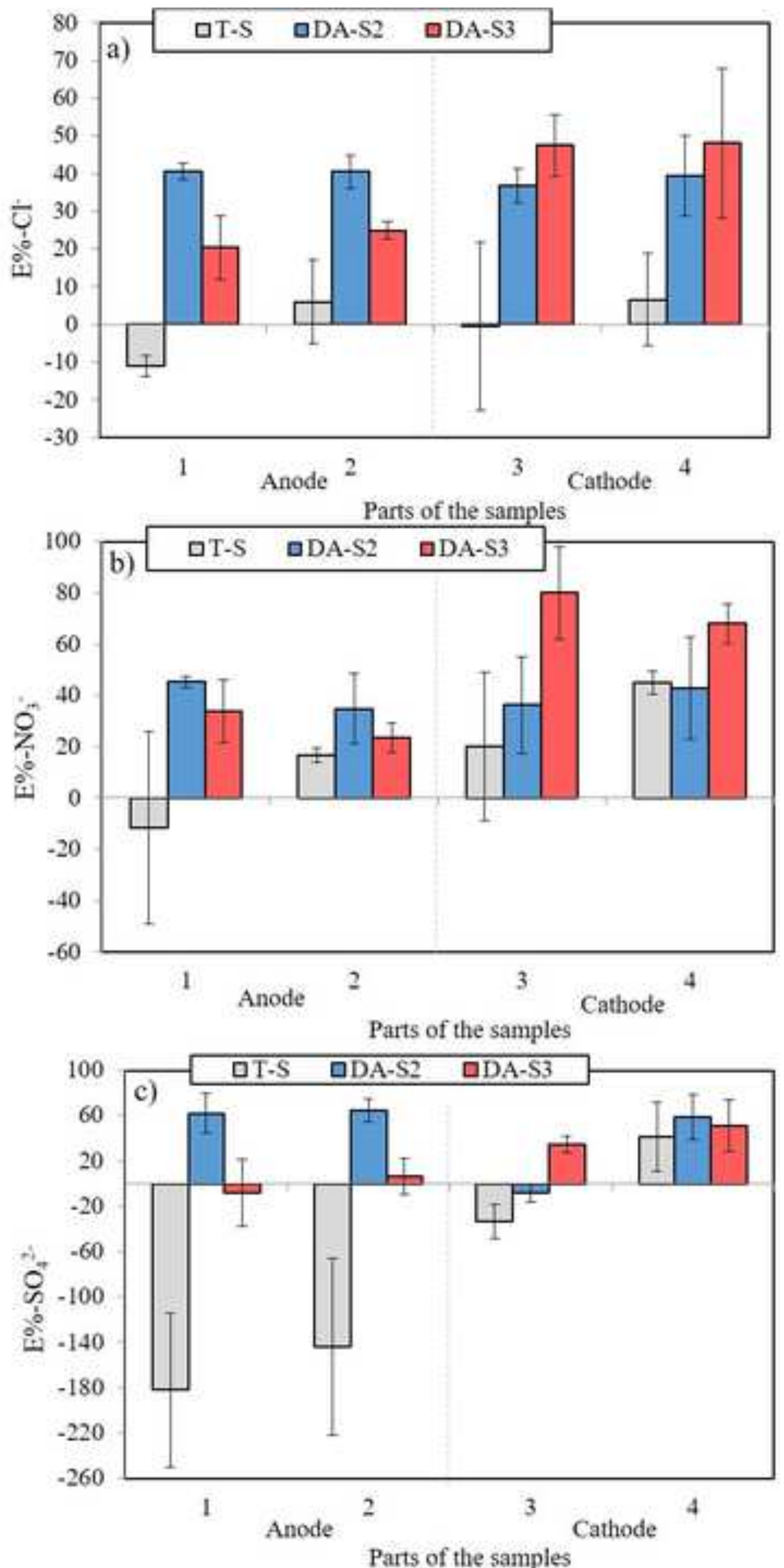

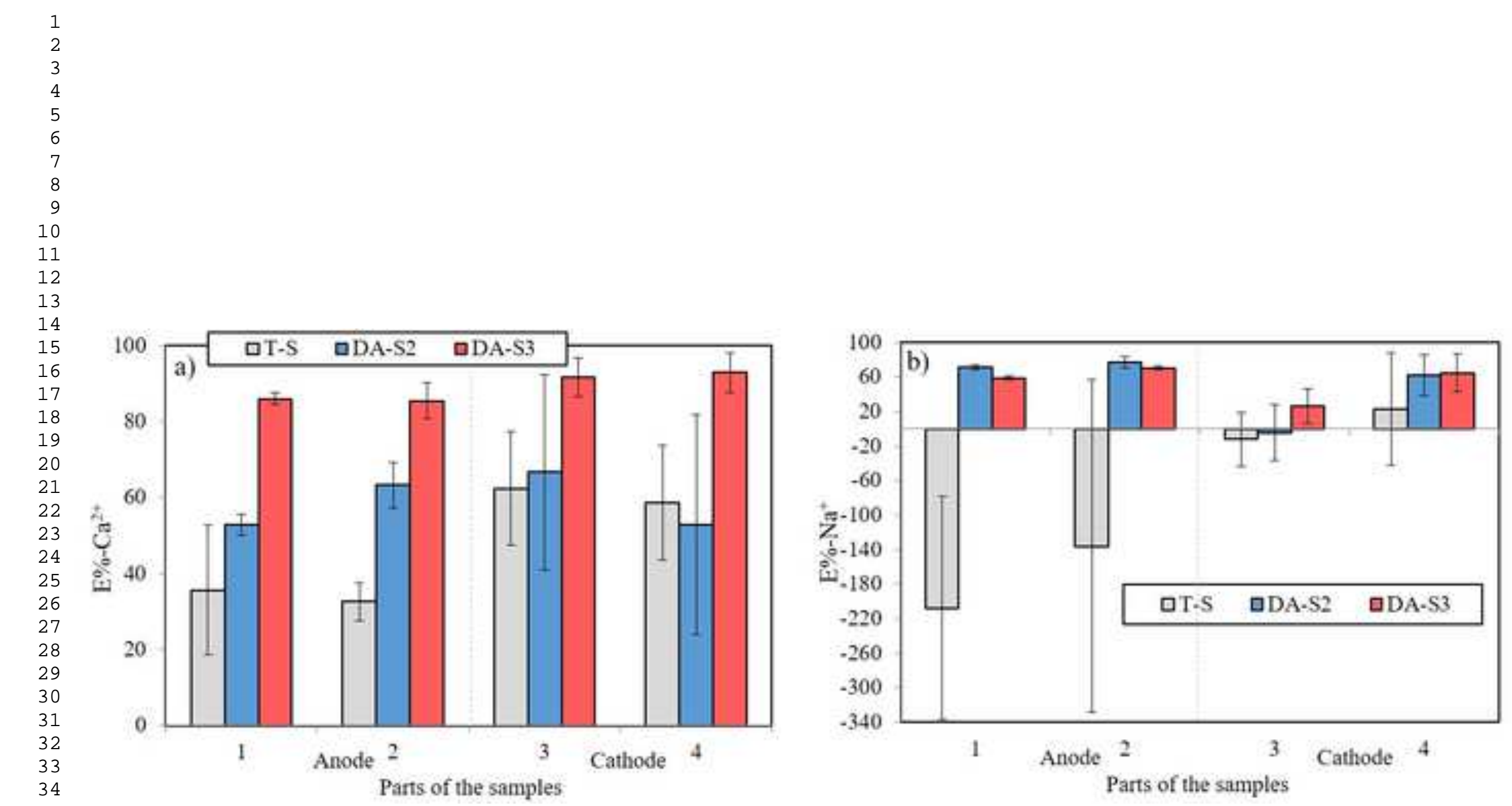
Table 1. Main properties of yellow sandstone calculated following different European standards and researches. Average initial ion content in the sandstone prisms.

\begin{tabular}{|c|c|c|}
\hline PARAMETERS & Yellow Sandstone & According to: \\
\hline Water accessible porosity [\%] & $13.24 \pm 0.31$ & RILEM 1980 [28] \\
\hline Mercury accessible porosity [\%] & $17.30 \pm 0.15$ & \\
\hline Capillary porosity [\%] & $11.47 \pm 0.25$ & [29] \\
\hline Capillarity coefficient $\left[\mathrm{kg} / \mathrm{m}^{2} \mathbf{s}^{0.5}\right]$ & $0.046 \pm 0.001$ & ICR-CNR 1985 [30] \\
\hline pH & $7.15 \pm 0.62$ & \\
\hline Conductivity $(\mu \mathrm{S} \mathrm{L} / \mathrm{g} \mathrm{cm}))$ & $0.014 \pm 0.00$ & [31] \\
\hline Zeta potential $(\mathrm{mV})$ & $-24 \pm 9.60$ & \\
\hline \multicolumn{3}{|l|}{ Initial ion content $(\% \mathrm{~g} / \mathrm{g})$} \\
\hline $\mathrm{Cl}^{-}$ & $0.248 \pm 0.009$ & \\
\hline $\mathrm{SO}_{4}{ }^{2-}$ & $0.021 \pm 0.003$ & \\
\hline $\mathrm{NO}_{3}^{-}$ & $0.335 \pm 0.017$ & \\
\hline $\mathrm{Ca}^{2+}$ & $0.021 \pm 0.003$ & \\
\hline $\mathrm{Na}^{+}$ & $0.018 \pm 0.005$ & \\
\hline
\end{tabular}

Table 2. Water content in \% (average value and standard deviation) of the poultice and of the stone before and after the treatments a applying the T-S setup and DA-S setups (DA-S2 and DAS3). The reduction of the water content (in \%) with respect to the initial one is also shown

\begin{tabular}{|c|c|c|c|}
\hline Water Content in the Poultice (\%) & Initial & Final & Reduction (\%) \\
\hline T-S & & & \\
\hline$\bullet \quad$ Medium 2 (PA2) & $41.26 \pm 2.28$ & $32.83 \pm 0.27$ & $20.45 \pm 0.65$ \\
\hline$\quad$ Cathode (PC) & $58.31 \pm 0.72$ & $44.99 \pm 0.15$ & $22.84 \pm 0.26$ \\
\hline DA-S2 & & & \\
\hline$\bullet \quad$ Medium 1 (PA1) & $580.51 \pm 7.09$ & $398.83 \pm 6.15$ & $31.30 \pm 1.06$ \\
\hline$\bullet \quad$ Medium 2 (PA2) & $41.26 \pm 2.28$ & $36.38 \pm 0.68$ & $11.84 \pm 1.64$ \\
\hline$\bullet \quad$ Cathode (PC) & $58.31 \pm 0.72$ & $53.16 \pm 1.27$ & $8.82 \pm 2.18$ \\
\hline DA-S3 & & & \\
\hline$\bullet \quad$ Medium 1 (PA1) & $580.51 \pm 7.09$ & $389.02 \pm 5.76$ & $32.99 \pm 2.91$ \\
\hline$\bullet \quad$ Medium 2 (PA2) & $41.26 \pm 2.28$ & $34.99 \pm 0.12$ & $15.21 \pm 0.30$ \\
\hline$\bullet \quad$ Cathode (PC) & $58.31 \pm 0.72$ & $50.33 \pm 0.26$ & $13.67 \pm 0.44$ \\
\hline Water Content in the Stone Prism (\%) & T-S & DA-S2 & DA-S3 \\
\hline \multicolumn{2}{|c|}{$1.94 \pm 0.13$} & $2.42 \pm 0.06$ & $2.77 \pm 0.08$ \\
\hline
\end{tabular}


Table 3: Total average amount ( $\mathrm{n}=3$ samples of stone per assembly) of $\mathrm{Cl}^{-}, \mathrm{NO}_{3}{ }^{-}, \mathrm{SO}_{4}{ }^{2-}, \mathrm{Ca}^{2+}$ and $\mathrm{Na}^{+}$retained in the different compartments (anode and cathode) during the Traditional setup and Double Anode setups (DA-S2 and DA-S3). Ion content retained in each of the different mediums that form the anodic compartment is shown. The total amount is the sum of the total average amount analyzed in each of the slices of the poultice (3 samples per layer representing a total of 9 samples analyzed by poultice).

\begin{tabular}{|c|c|c|c|c|c|c|}
\hline \multirow[b]{3}{*}{ Ion } & \multicolumn{6}{|c|}{ Ion content in each compartment (mg/compartment) } \\
\hline & \multicolumn{3}{|c|}{ Anode } & \multicolumn{3}{|c|}{ Cathode } \\
\hline & T-S & DA-S2 & DA-S3 & T-S & DA-S2 & DA-S3 \\
\hline $\mathrm{Cl}^{-}$ & $\begin{array}{c}241.66 \pm 25.3 \\
2\end{array}$ & $\begin{array}{c}281.28 \pm 40.0 \\
6\end{array}$ & $\begin{array}{c}327.06 \pm 11.1 \\
6\end{array}$ & $26.01 \pm 10.10$ & $24.04 \pm 1.98$ & $20.28 \pm 0.73$ \\
\hline $\mathrm{NO}_{3}$ & $\begin{array}{c}287.78 \pm 91.8 \\
8\end{array}$ & $\begin{array}{c}412.65 \pm 108 . \\
88\end{array}$ & $\begin{array}{c}517.57 \pm 20.9 \\
3\end{array}$ & $27.42 \pm 11.87$ & $16.27 \pm 6.55$ & $9.76 \pm 2.92$ \\
\hline $\mathrm{SO}_{4}^{2}$ & $19.17 \pm 1.55$ & $26.63 \pm 3.89$ & $31.01 \pm 10.06$ & $12.98 \pm 6.75$ & $2.66 \pm 1.46$ & $2.23 \pm 0.74$ \\
\hline $\mathrm{Ca}^{2+}$ & $44.95 \pm 16.12$ & $65.61 \pm 8.74$ & $\begin{array}{c}125.01 \pm 55.9 \\
8\end{array}$ & $1.62 \pm 1.10$ & $0.80 \pm 0.42$ & $0.35 \pm 0.12$ \\
\hline \multirow[t]{3}{*}{$\mathrm{Na}^{+}$} & $\begin{array}{c}269.83 \pm 107 . \\
29\end{array}$ & $\begin{array}{c}193.05 \pm 69.6 \\
2\end{array}$ & $\begin{array}{c}183.31 \pm 84.9 \\
6 \\
\end{array}$ & $\begin{array}{c}324.41 \pm 128 \\
99\end{array}$ & $\begin{array}{c}324.72 \pm 154 . \\
94\end{array}$ & $309.04 \pm 3.81$ \\
\hline & \multicolumn{6}{|c|}{ Ion content in each medium of the anodic compartment (mg/medium) } \\
\hline & \multicolumn{2}{|c|}{ T-S } & \multicolumn{2}{|c|}{ DA-S2 } & \multicolumn{2}{|c|}{ DA-S3 } \\
\hline Ion & Medium 1 & Medium 2 & Medium 1 & Medium 2 & Medium 1 & Medium 2 \\
\hline $\mathrm{Cl}^{-}$ & - & $\begin{array}{c}241.66 \pm 25.3 \\
2\end{array}$ & $63.33 \pm 3.56$ & $\begin{array}{c}217.95 \pm 24.7 \\
6\end{array}$ & $101.43 \pm 5.69$ & $225.63 \pm 2.20$ \\
\hline $\mathrm{NO}_{3}$ & - & $\begin{array}{c}287.78 \pm 91.8 \\
8\end{array}$ & $\begin{array}{c}145.61 \pm 47.9 \\
0\end{array}$ & $\begin{array}{c}267.03 \pm 29.0 \\
8\end{array}$ & $\begin{array}{c}251.63 \pm 12.9 \\
4\end{array}$ & $265.94 \pm 1.86$ \\
\hline $\mathrm{SO}_{4}^{2}$ & - & $19.17 \pm 1.55$ & $9.40 \pm 0.10$ & $17.23 \pm 2.65$ & $17.82 \pm 5.35$ & $13.19 \pm 1.76$ \\
\hline $\mathrm{Ca}^{2+}$ & - & $44.95 \pm 16.12$ & $33.72 \pm 5.98$ & $31.89 \pm 0.20$ & $53.92 \pm 14.56$ & $71.10 \pm 25.02$ \\
\hline $\mathrm{Na}^{+}$ & - & $\begin{array}{c}269.83 \pm 107 . \\
29\end{array}$ & $33.83 \pm 8.68$ & $\begin{array}{c}159.22 \pm 40.5 \\
5\end{array}$ & $1.40 \pm 0.83$ & $\begin{array}{c}181.82 \pm 59.2 \\
4\end{array}$ \\
\hline
\end{tabular}

